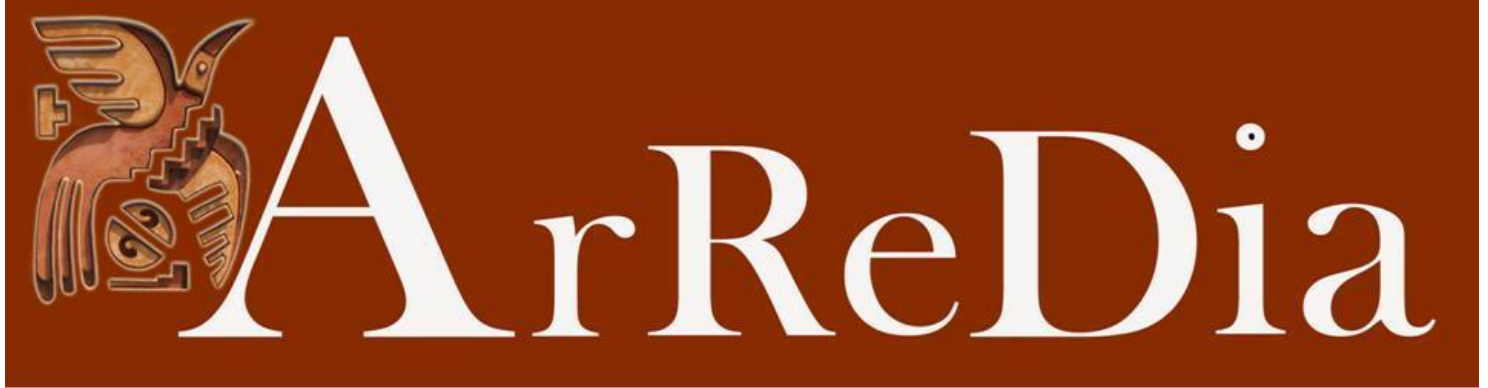

Revista da Faculdade de Comunicação, Artes e Letras / UFGD

\title{
BRUXAS, DEMÔNIOS, MONSTROS, FANTASMAS E LOUCURA: QUATRO NARRATIVAS RUSSAS
}

\author{
Witches, demons, monsters, ghosts and madness: four Russian \\ narratives
}

\author{
Rodrigo do Prado Bittencourt ${ }^{i}$ \\ Universidade de Coimbra
}

Resumo: Este artigo analisa quatro novelas de Gógol (1809-1852). Duas novelas são sobre o funcionalismo russo de baixo escalão e suas péssimas condições de vida. Elas se passam em São Petersburgo e contêm desdobramentos fantásticos. Os outros dois textos têm características de narrativa folclórica e descrevem a ação de seres sobrenaturais e acontecimentos extraordinários. A vida nas pequenas aldeias russo-ucranianas descrita por Gógol pauta-se na independência típica dos cossacos e no gozo dos prazeres. Além disso, há a integração social das mais diversas personagens, mesmo das bruxas. Tratase de outra realidade, bem distante daquela formada pelo capitalismo moderno e pela herança de culpabilidade deixada pela moral cristã.

Palavras-chave: Novelas. Gógol. Fantástico. Burocracia. Folclore.

\begin{abstract}
This article analyzes four novels by Gógol (1809-1852). Two novels are about low-level Russian functionalism and its poor living conditions. They take place in St Petersburg and contain fantastic outcome. The other two texts have characteristics of folkloric narrative and describe the action of supernatural beings and extraordinary events. The life in the small RussianUkrainian villages described by Gógol is based on the typical independence of the Cossacks and the enjoyment of pleasures. In addition, there is the social integration of the most diverse characters, even witches. It is another reality, far away from that formed by modern capitalism and by the inheritance of fault left by Christian morality.
\end{abstract}

Keywords: Novels. Gógol. Fantastic. Burocracy. Folklore.

Este artigo analisa quatro novelas de Gógol. Duas ambientadas em São Petersburgo, com protagonistas pertencentes ao baixo escalão do funcionalismo público, e duas voltadas para as tradições folclóricas russo-ucranianas e para as pequenas vilas deste país. A burocracia russa e as más condições de vida de seus funcionários subalternos é um tema recorrente não apenas na obra de Gógol, mas de toda a literatura russa do século XIX, estando presente de modo marcante também em Dostoiévsky, por exemplo. Assim, Gógol pode ser visto como um precursor e como referência para o que de melhor se produziu após ele.

No que se refere às tradições folclóricas, no entanto, por maiores que tenham sido os méritos de suas narrativas, elas quedaram sem uma continuação perene e sólida. Com efeito, não serão muitas as grandes produções literárias russas do século XIX que abordarão o folclore popular, como fez Gógol. Isso não pode deixar de ser inserido no contexto da emergência dos Estudos Folclóricos, 
enquanto ciência antropológica de relativa importância em toda a Europa durante grande parte do século XIX, e de sua decadência, no final do mesmo século e no início do seguinte. Os textos de Gógol aqui analisados, como se pretende mostrar, não podem ser vistos como simples coleta de histórias populares, pois contêm a efabulação e o desenvolvimento de técnicas narrativas próprias da Literatura. Como se verá, essas novelas são de grande valor estético e de extrema importância não apenas histórica e documental, mas também artística. Após sua análise, há uma breve reflexão acerca do folclore; ela nasce da leitura das duas novelas e complementa seu estudo.

O que une estas quatro narrativas é o temática voltada para o fantástico, abarcando não apenas as tradições folclóricas tradicionais, mas até mesmo a moderna vida da grande capital nacional e uma das principais metrópoles do Leste Europeu, no século XIX. Há um tratamento diferente desta temática nestas duas classes de narrativas: nas narrativas tradicionais, o fantástico aparece como um elemento perfeitamente integrado ao cotidiano, podendo ser mesmo influenciado e de certo modo até controlado pelas personagens humanas; já os contos que se passam em São Petersburgo apresentam o fantástico como disrupção, como elemento perturbador da ordem e originado das condições extremas e insuportáveis que ela obriga os funcionários públicos de baixo escalão a suportar.

Se nas histórias folclóricas, o fantástico pode surpreender e causar medo, ele jamais causa o pavor e a paralisia que são provocadas pela aparição do fantasma de Akáki Akákievitch, em busca de seu capote. Isto porque o fantástico faz parte da ordem social das pequenas aldeias ucranianas descritas nessas narrativas (mesmo as bruxas frequentam os cultos religiosos, como os demais). Enquanto as narrativas da grande capital apresentam um elemento fantástico contestador da ordem social vigente; denunciador das injustiças e aporias provocadas pela extrema situação de dominação e pela rigorosa hierarquia.

\section{Diário de um louco}

O Diário de um louco pode parecer tão somente um texto sobre a idiossincrasia absoluta - aquela de alguém que vive numa realidade toda particular, percebida apenas por ele, uma vez que fruto de sua imaginação doentia -, mas ele é mais; sem deixar de ser também isso.

A narrativa traz uma percepção crítica do funcionalismo público e da sociedade de classes da Rússia czarista. As constantes humilhações, a hierarquia rígida e com divisões quase infinitas, a falta de perspectiva de ascensão social e de dignidade, o tédio, o parasitismo dos empregados públicos, a desigualdade de classes como impeditiva de relacionamentos amorosos, a solidão, etc. Enfim, 
toda a gama de situações e condições porque passava um homem em sua posição social, em sua época e em seu país é analisada aqui.

Há cachorros que falam e trocam cartas entre si. Há também um funcionário de baixo escalão que se pensa rei da Espanha, mas o mais gritante não são essas extravagâncias, mas sim o fato de elas parecerem perfeitamente concatenadas com a realidade experimentada pela protagonista antes de sua loucura. É esta concatenação que denuncia o absurdo no interior da normalidade, da vida real.

O tratamento violento por parte da instituição de saúde mental não é visto aqui com um olhar especialmente crítico - o que se mostra até certo ponto compreensível, pela época em que o texto foi escrito e pelo fato de não ser este seu foco principal. A principal crítica aqui se refere mesmo ao vazio e à artificialidade de uma hierarquizada e autoritária sociedade, que divide radicalmente seres iguais entre si: todos humanos, todos repletos dos mesmos anseios e necessidades. Afinal, até que ponto a loucura do funcionário não é fruto de seu desejo de fugir a esta realidade opressora? Em qual medida seu desejo de ascensão social e de um casamento que lhe é vedado socialmente contribuem para sua fuga da realidade?

Em certo sentido, subsiste também uma questão de cunho mais profundo e filosófico: o que é a realidade? Se a vida parece ser uma mentira para agradar convenções sociais absurdas, a loucura não parece mais autêntica e mais real? Percebe-se, enfim, que a normalidade demonstra estar tão doentia que já não se pode mais encarar a loucura como um mero desvio, mas ela parece ser quase que uma necessidade humana.

A profunda combinação de análise psicológica e crítica social, tão característica de Gógol e outros autores eslavos, aparece aqui com força e originalidade. Lembrando Crime e Castigo, de Dostoiévsky, e Os sete enforcados, de Andreiev. A sociedade russa da época é vista como desencadeadora de distúrbios mentais, por estar ela própria fundada em paradigmas doentios. Esta obra filiase, portanto, a um grande conjunto de textos russos de então, que apresentam a crítica das bases políticas, sociais, econômicas e culturais de uma sociedade que passava por intensa modernização, mas que ainda estava longe de promover as reformas liberais já realizadas nos países da Europa Ocidental. O próximo texto analisado, aliás, também se enquadra neste grupo de obras de análise social com viés crítico.

\section{O Capote}

Não se pode ler esta novela sem uma grande expectativa. Afinal, disse Dostoiévisky, a respeito de si e de sua geração de escritores russos: “Todos nós 
descendemos d'O Capote" (DOSTOIÉVSKY apud BEZERRA, 1990, p. 25). Mas o que esta obra de Nikolai Vassílievitch Gógol (1809-1852), publicada em 1842, tem de tão importante? Pode-se pensar em vários fatores, que serão tratados a seguir.

Há um misto de realismo e fantástico no texto de Gógol e existe um casamento muito bem feito entre estes dois aspectos da obra. Isso explica o fato de Akáki Akákievitch ser uma personagem tão estranha. De fato, ele já estava destinado a ser fantasma desde seu nascimento e sua vida parece absurda (e realmente o é) porque em vida, sem que ele ou os outros soubessem, ele já era um fantasma. Daí a coesão da obra: não espanta que ele se transforme e passe a atormentar os donos de capotes, pois ele nunca foi uma pessoa completa, mas apenas uma espécie de suporte, de substrato, à monomania. A princípio foi a monomania de copiar; depois a obsessão por um capote. Palerma e coisificado, ele não pode aspirar a nada de grandioso e muito menos trazer em si a multiplicidade humana. Fruto de uma sociedade capaz de fazer isso com suas vítimas mais indefesas, a história desta personagem é extremamente política, pois capaz de questionar todo o ordenamento social vigente. Ela é um golpe contra a direita e os conformistas; um golpe contra a elite, que jamais se importa com aqueles que são pisoteados por ela; um golpe contra a desumanização do humano, perpetrada pela desigualdade e pelo autoritarismo.

Em segundo lugar, deve-se levar em conta o narrador, que se apresenta de modo irônico e jocoso diante da história narrada e do próprio leitor, fazendo brincadeiras sobre o gesto de narrar. Ele diz que esqueceu determinado detalhe da narrativa em certo momento e em outro diz que não poderia saber o que se passava na mente da protagonista; ele, que já havia devassado a mente desta personagem diante do leitor. Isso demonstra um texto muito bem preparado e rascunhado: do começo ao fim o narrador parece saber aonde quer chegar e não demonstra tibieza ou incertezas. Gógol deve ter revisado muitas vezes a sua novela, para chegar a tal estado de acabamento. Até porque a passagem do momento de crítica social e de humor para o momento final, fantástico e macabro, não se faz notar como algo brusco e forçado. Ao contrário, parecem muito bem integradas as distintas partes do texto e a piada final muito contribui para fortalecer esta coesão. Este é um dos elementos que fortalece este texto e que contribuiu para sua consolidação na História da Literatura Russa.

Além disso, deve-se ter em mente que $O$ Capote representou uma verdadeira revolução literária na Rússia de então. Isto, entre outros motivos, pelo modo como Gógol reproduz a linguagem popular cotidiana. De fato, é muito moderna sua "transcrição" da fala de Akáki Akákievitch, com sua gagueira nervosa, sua insegurança, suas sentenças incompletas, suas demoras... É algo que rompeu completamente com os padrões do bom gosto e do estilo tido como recomendável, na época. 
O quarto ponto a ser colocado é o da crítica social à desigualdade, ao autoritarismo, à injustiça do Judiciário e à burocracia pública. Pontos que serão essenciais para a obra de Dostoiévsky, sobretudo, mas também para as de outros autores russos do século XIX. Principalmente no que se refere à crítica à burocracia russa, $O$ Capote tornou-se um marco histórico. Isto porque o tema da desigualdade e da miséria, muito presente nesta narrativa e talvez de forma mais objetiva e crua que nas demais grandes obras russas, é um tema universal, já trabalhado pelas literaturas de outros países, mas o tema da burocracia, se bem que possa estar presente em outras literaturas, não deixa de ser uma peculiaridade da arte russa do século XIX e Gógol não apenas ataca este problema social com pujança, mas o faz com marcante estilo.

Em quinto lugar, embora tratando-se de uma narrativa curta, Gógol consegue criar personagens marcantes: o alfaiate Pietróvitch e a pessoa importante a quem Akáki Akákievitch recorre para reaver seu capote e de quem não se sabe o nome com precisão: seria ele Ivan Abrâmovitch ou Stepan Varlâmovitch? O alfaiate bêbado se fazia de bom russo para ter desculpas para embriagar-se nos dias de festa religiosa, chamando sua esposa de "mundana" e "alemã", quando esta lhe censurava a embriaguez. Enquanto a pessoa importante treinara em frente ao espelho o tom de voz, para intimidar seus subordinados, assim que soube de sua nomeação; tolo, vazio e imensamente arrogante só tinha três frases para os que se encontravam em menor posição hierárquica: "Que petulância é essa? Será que o senhor sabe com quem está falando? Entende diante de quem se encontra?" (GÓGOL, 1990a, p. 49.)

Já Akáki Akákievitch apresenta-se como uma personagem marcante por uma razão peculiar: um homem que é apaixonado pelo maçante serviço de copiar textos oficiais é profundamente interessante. Ele chegava mesmo a ter predileção por certas letras e mesmo em suas horas de lazer copiava coisas, apenas por diversão. Trata-se, porém, de alguém tão coisificado e vítima da reificação que não chega a tornar-se uma personagem inteiriça; una. Ele é mais um artifício que uma personagem e esta sua configuração explica-se pelo caráter de modernidade e de investigação conceitual que Gógol quis dar a seu texto. É inegável que Akáki Akákievitch não chega a ter o grau de vida e de autenticidade que Pietróvitch ou a pessoa importante têm, mas isto é intencional: esta coisificação integra a denúncia com relação aos efeitos nocivos da doentia sociedade russa de então e, particularmente, da desigualdade social e da insana disciplina do funcionalismo estatal. Além disso, faz parte do estilo moderno e inovador do texto. Aliás, partindo da proposta do texto, ele não poderia ser de outro jeito: como denunciar a nulidade de uma sociedade senão com uma personagem nula, quase coisa? Akáki Akákievitch parece até mesmo uma espécie de precursor d'O Cavaleiro Inexistente, de Ítalo Calvino. 
Por fim, mas não menos importante, há a questão topográfica, que não é uma característica típica da literatura russa, mas sim da francesa (vide Os Miseráveis, de Victor Hugo, ou O Pai Goriot e Eugénie Grandet, ambos de Balzac). Dostoiévsky descreve muito bem a prisão de Recordações da Casa dos Mortos, o quarto de Raskólnikov ou o prédio em que ele assassina a usurária e sua irmã, mas não se preocupa em descrever tão bem a cidade em si. Gógol já o faz. Temse mesmo a sensação de estarmos a caminhar com Akáki Akákievitch pelas ruas de São Petersburgo. Ou seja, a descrição espacial aqui não busca apenas realizar uma tarefa essencial para o desenvolvimento da ação, mas ela tem valor por si própria, uma vez que consegue constituir-se num trunfo estético.

\section{Noite de Natal}

Essa é uma narrativa literária e folclórica russo-ucraniana, que traz em si referências à História do século XVIII (dissolução do exército cossaco, Guerra Turco-Russa e Iluminismo Russo). Trata-se de um texto sincrético, que mistura cristianismo e paganismo e aborda mesmo as práticas religiosas mais oficiais (como a confissão e a penitência) de um modo pagão e popular.

Noite de Natal mistura a ingenuidade de um lugar e um tempo onde a ideia de pecado e maldade praticamente não existem com a presença de seres sobrenaturais e eventos fantásticos. Ler este texto traz aprendizagens sobre uma cultura muito distinta da brasileira e a volta das alegrias da infância; são novidades e surpresas do começo ao fim.

O ferreiro Vakula é o herói desta narrativa. Ele habita uma pequena aldeia ucraniana, no século XVIII, momento em que a Ucrânia pertencia à Rússia. Como herói, ele deve realizar uma difícil tarefa (conseguir botinhas como as que czarina usa) para alcançar o prêmio desejado: casar-se com a mais bela garota da aldeia (Osana, de apenas dezesseis anos), filha de Tchub. Para isso, ele utilizará de poderes fantásticos (os do diabo) domando justamente o inimigo que tanto ódio lhe tinha.

Este enredo, não muito complexo, é muito comum em narrativas folclóricas de todo o mundo. O folclore trabalha com personagens-tipo, invariavelmente dotadas de um caráter unívoco e simples, sem questionamentos internos e indecisões. Ele configura-se como um tipo de literatura focado numa descrição factual cujos valores não são contestados, pois reproduzem as crenças e opções do grupo. Não é próprio deste tipo de literatura avançar numa discussão a respeito de dúvidas e incertezas de uma personalidade multifacetada. $\mathrm{O}$ remorso de Osana, ao pensar que poderia ter perdido o ferreiro para sempre, ou os melindres da consciência religiosa de Vakula, por ter pensado em suicídio e perdido as celebrações religiosas de Natal, são, portanto, características de uma 
literatura de matiz erudito. O compadre de Tchub, no entanto, só pensa em beber e é um vagabundo (no sentido estrito do termo), sempre vagando pela aldeia em busca de algo que possa espantar seu tédio e/ou lhe proporcionar comida e vodca. Este, sim, é um personagem-tipo, como as comuns em narrativas do folclore.

Se Vakula demonstra ter uma consciência religiosa e arrependimento, porém, como se pode falar em ausência de pecado? Isso se dá porque o que existe em Noite de Natal não é propriamente uma ideia de culpa moral, mas sim de pureza ritual; o que é muito distinto. Vakula, por ser, além de ferreiro, um artista sacro (ele realiza pinturas de painéis e quadros religiosos) é tido como alguém poderoso no campo do sobrenatural. Além disso, ele é poderoso também no campo natural, tendo uma força descomunal. As suas penitências são, portanto, um modo de purificar-se mágica e misticamente para não perder nada de sua pujança natural e de poder sobrenatural. Não há nele um arrependimento moral e uma reflexão sobre seu ato, mas a execução ritualística de uma prática oficial do Catolicismo Ortodoxo (a confissão seguida de penitência) para voltar a estar em condições de enfrentar as forças do mal e até mesmo usar delas a seu favor, quando lhe aprouver. Ora, se não há pecado, não há culpa; daí o traço de inocência que nos remete vivamente à infância. Afinal, dentro de uma sociedade historicamente cristianizada, pessoas religiosas (e mesmo as que não o são) assumem uma ideia de responsabilidade e culpa. Há várias formas de culpa secularizada presentes na política, nas relações sociais e na cultura. A única vivência desprovida de culpa é a da infância e isso apenas enquanto os adultos não forem capazes de ir incutindo nos pequeninos o fel da culpa e da negação de si mesmo.

Mesmo o remorso de Osana aparece ao leitor como um deus ex machina, que existe apenas para engrandecer Vakula. Ele soa deslocado do contexto da narrativa e cumpre a função de garantir ao herói o prêmio ideal: um casamento feliz e não o sofrimento de um casamento que se deu apenas por obrigação, sem amor de ambos os noivos. Além disso, a tristeza de Tchub com relação à descoberta de que Solokha tinha vários amantes serve apenas para que ele possa desistir de casar-se com a mãe de Vakula e, assim, este possa casar-se com Osana, sem incorrer em incesto. A ausência de culpa é tão grande que o pretensamente devoto protagonista tem uma mãe bruxa, amante do diabo e de diversos homens e não se preocupa em convertê-la (obrigação de todo cristão). Tampouco se pode considerar que ele não soubesse, ao menos, de sua condição de bruxa, pois Osana lhe pergunta sobre isso logo no começo da narrativa. Será que ele não acreditava no que os demais falavam? Será que fazia de conta que não via e não sabia de nada? Não se sabe. Não tem importância para a narrativa e justamente o fato de não ser relevante mostra como culpa e responsabilidade por educar e/ou 
converter os demais são coisas que passam longe da pequena aldeia, onde cada um busca o que lhe dá mais prazer, em relativamente harmoniosa convivência com o grupo. Aliás, Solokha, apesar de suas práticas, também vai à igreja participar das celebrações religiosas, o que mostra que mesmo as bruxas são integradas à sociedade local e que ninguém é marginalizado por sua condição social/espiritual ou por seu estilo de vida.

Além de não haver culpa, não há maldade. Os rapazes e moças do povoado brincam entre si de forma às vezes violentas e ninguém se sente desgostoso com isso; não há altercações ou brigas. Mesmo quando há roubo e acusações de adultério, estas coisas são tratadas como naturais; coisas que acontecem. Se estes atos geram brigas, ninguém parece se importar muito com isso e tampouco parece que estas brigas sejam levadas a sério, mesmo por quem nelas está envolvido. A narrativa simplesmente as deixa de lado, como coisa normal e sem importância.

Assim, tem-se uma pequena comunidade em que todos se conhecem e cada um se vira como pode para ser feliz, conquistando os prazeres que almeja, sem sentimento de culpa ou de responsabilidade por outro além de si próprio e de suas crianças, evidentemente. Todos, inclusive as forças malignas, têm seu lugar na comunidade e o único que é sempre logrado é o diabo, eterno derrotado. Diabo fraco significa culpa ausente. Não foi em vão que a Idade Média foi tão profusa em demonologia e tanto enfatizou o poder das trevas: quanto mais força atribui-se ao diabo, maior medo e sentimento de culpa por parte dos fiéis. Este tipo de vivência religiosa, aliás, subiste até hoje. A inocência quase infantil dos cossacos da pequena aldeia ucraniana mostra uma maneira diferente de se viver; talvez perdida para sempre pela humanidade.

Outro texto que apresenta este estilo de vida é Viy, que será analisado a seguir e que também insere o fantástico em meio ao cotidiano de uma pequena comunidade do interior da Ucrânia (que então fazia parte da Rússia). Nesta outra narrativa, Gógol dá mais ênfase ao aspecto macabro da lenda folclórica e o terror ganha mais espaço. Mesmo assim, os homens ainda podem dominá-lo, desde que saibam o modo correto de lidar com as forças sobrenaturais.

\section{Viy}

Em Viy, o leitor depara-se com o folclórico e com o humano. O folclore nem sempre se preocupa com a minúcia e o detalhamento que humanizam as personagens de uma diegese. Outros modos de Literatura, sim; sobretudo, desde o século XIX. Embora, essa tendência não tenha se iniciado aí, mas possa ser percebida já em Homero e na Bíblia. A compaixão de Aquiles diante do sofrimento de Príamo, que culmina com a entrega ao venerando rei do corpo de Heitor; bem como a hesitação e o receio de Telêmaco, diante dos abusos dos 
pretendentes de Penéolpe são exemplos disso. Bem como o dilema moral de Davi, evitando matar Saul, ou o de Jônatas, amigo do inimigo de seu pai. Ou ainda o sofrimento de Jesus no Horto das Oliveiras, chegando a suar sangue, em sua angústia. Muitos outros exemplos como estes demonstram um cuidado em descrever o pensar e o sentir das personagens, evitando fazer da narrativa uma mera descrição de fatos. Viy também apresenta elementos de caracterização da vida moral de algumas das suas personagens, introduzindo assim dilemas íntimos e pessoais às sequências factuais tipicamente folclóricas.

A narrativa oral de origem ucraniana, portanto, ganha o influxo de uma análise psicológica e histórica que a distancia do arquétipo e da atemporalidade típicas do folclore. Este, entretanto, não aparece somente no tema, mas marca presença também na descrição dos costumes, da alimentação e da arquitetura tradicionais, realizando uma função memorialística e preservacionista. Além disso, o folclore mostra-se presente no modo como a personagem principal, o estudante Khomá, reage ao sobrenatural. É típica das narrativas folclóricas a integração entre o fantástico e sobrenatural ao cotidiano, sem reservas ou teorizações.

A possessão demoníaca pode até parecer convencional e mesmo lembrar a um leitor do século XXI, filmes que tenham como tema o exorcismo. O final da obra, entretanto, desmancha esta aproximação com a maneira cristã ortodoxa de tratar o tema. O nome Viy refere-se a um ser do folclore ucraniano, cujas pálpebras são descomunais, chegando até o chão. É ele e não o demônio - um ente maligno da ortodoxia judaico-cristã - que mais atemoriza Khomá e acaba por matá-lo.

O estudante Tibéri Górobiets, ao comentar a morte de seu amigo, revela a receita mágica para vencer o demônio, as bruxas e os monstros. Assim, o fantástico e o sobrenatural demonstram-se mais uma vez possíveis de serem entendidos e até vencidos ou controlados, como já se percebia pelos atos de Khomá, que despreocupadamente assediava belas raparigas do local em que estava a fazer seu trabalho de exorcismo e dançava alegremente no intervalo entre os combates espirituais. O demoníaco e monstruoso não deve, pois, causar medo aos que sabem como lidar com este tipo de coisas, mantendo sempre a calma e usando de seus conhecimentos tradicionais e sua astúcia.

Assim, sem deixar de ser assustador e de mobilizar todo um rico imaginário ligado à ortodoxia religiosa ocidental, o texto traz novamente a ligação pagã entre o ser humano, a natureza, o fantástico e o sobrenatural. Ligação que fora perdida, com a consolidação do tipo de Cristianismo que historicamente estabeleceu-se na Europa e esta constatação é válida tanto para sua ramificação Latina, a Igreja de Roma, quanto para as diversas Igrejas 
Ortodoxas que emanaram do Império Romano do Oriente: a Igreja Ortodoxa Russa, a Grega, a Síria, a Armênia, etc.

Khomá realiza exorcismos, mas está longe de ser virtuoso. É mais um pícaro ou anti-herói que um santo. Suas façanhas constituem a vitória do homem do povo sobre os letrados e intelectuais. Afinal, por mais que seja um estudante, ele é pobre, simples e gosta de misturar-se com os homens do povo. O que domina os seres fantásticos e sobrenaturais não é o conhecimento livresco ou a santidade referenciada pela ortodoxia religiosa, mas a sabedoria popular, pertencente aos simples. São os explorados e humilhados os mais capazes de lidar com as forças não humanas. Assim, Viy consegue não apenas honrar as tradições culturais de um povo e suas classes mais baixas, como também se torna universal por construir a visão de um mundo plenamente inteligível, por mais estranho que pareça ser, em que seres humanos, demônios, monstros e bruxas convivem cotidianamente, sempre com o predomínio daqueles humanos que respeitam e conhecem os ensinamentos da sabedoria popular tradicional.

De certo modo, o texto honra o homem do povo que está presente no interior dos três estudantes. É para associar estes estudantes aos cossacos e demais homens práticos e voltados a trabalhos manuais que o início do texto faz a separação entre os estudantes ricos e pobres e entre os da capital e os provincianos. Mesmo a descrição de ações de caráter ainda infantil em meio aos estudantes, como as brigas ou o demasiado interesse pelos animais (que leva a atos como o de manter um filhote de pardal no bolso em meio à aula) serve para aproximar mais estes estudantes da vida simples dos homens do povo. Afinal, seus traços infantis permitem aproximá-los das crianças das classes populares com muito mais acerto que se poderia aproximar os adultos destas mesmas categorias.

Além disso, Viy atende a mais profunda ambição humana: o controle do misterioso e do imponderável. Ele faz tudo isso sem fazer de suas personagens meros tipos sociais, subservientes aos interesses da narrativa, mas contempla também a análise social e psicológica tão rica quanto de outros textos deste autor. Aliás, a análise da psique humana que marcará a obra de Gógol e influenciará imensamente outros autores de cultura eslava. Desde Viy percebe-se já a capacidade de Gógol de produzir obras de fina análise social e psicológica e de requintada e zombeteira ironia.

\section{O folclore como afirmação do "eu"}

As análises positivistas do folclore, de feitio determinista e generalizante, bem como seu uso por Estados Autoritários e Totalitários, como a Alemanha Nazista (a própria suástica tem origem folclórica), acabou por desprestigiar o 
estudo do folclore, que teve seu auge no século XIX. Este ramo de estudos, entretanto, não tem cunho conservador ou generalizante, embora tenha sido usado também por pessoas que tinham a intenção ou de criar a ideia de uma base cultural comum a toda humanidade ou de especificidade particular de um povo:

\begin{abstract}
Em outras palavras, como todo nacionalismo, o nazismo exaltou de um modo passadista a tradição histórico-cultural alemã ou mais largamente germânica (ou que se poderia tentar anexar a um germanismo). Mas nessa exaltação - que reanima tanto o folclore e a Volkslied, o imaginário do campo do pós-romantismo e das cidades da Hansa, as "ligas" (Bünde) estudantis antinapoleônicas, as corporações medievais, as ordens cavaleirescas, o Sacro-Império etc.-, uma mitologia (digamos, a de Erda, de Odin e de Wotan) já há muito em desuso, apesar de Wagner e de alguns outros, não poderia contar a não ser para alguns intelectuais e artistas, a rigor, para alguns professores ou educadores. Em suma, esse tipo de exaltação não possui nada de específico (assim como a exaltação de Joana d'Arc pelo Estado francês de Pétain). (LACOUE-LEBARTHE; NANCY, 2002, p. 20, grifo meu).
\end{abstract}

Em sentido oposto, o resgate do folclore pode ser de extrema importância na luta por uma sociedade mais plural e menos preconceituosa. No caso ucraniano, que é o caso dos dois textos de Gógol acima analisados, o resgate do folclore veio a contribuir para fortalecer a identidade nacional e, assim, afirmar a soberania de seu povo diante do domínio russo, que então se fazia presente.

No Brasil, o maior estudioso do tema foi, sem dúvida alguma, Luís da Câmara Cascudo, que recolheu diversas narrativas, vocábulos, descrições de práticas culturais, de danças e comidas de diversas regiões do país. Percebe-se nos livros dele o mesmo modelo já relatado acima: histórias curtas, com um único núcleo narrativo, personagens-tipo, ausência de detalhes descritivos de comportamentos ou cenário e aceitação do fantástico como realidade corriqueira e banal. Câmara Cascudo define folclore assim:

Todos os países do Mundo, raças, grupos humanos, famílias, classes profissionais, possuem um patrimônio de tradições que se transmite oralmente e é defendido e conservado pelo costume. Esse patrimônio é milenar e contemporâneo. Cresce com os conhecimentos diários desde que se integrem nos hábitos grupais, domésticos ou nacionais. Esse patrimônio é o FOLCLORE. Folk, povo, nação, família, parentalha. Lore, instrução, conhecimento na acepção da consciência individual do saber. Saber que sabe. Contemporaneidade, atualização imediadista do conhecimento (CASCUDO, 1967, p.9).

Por esta definição, percebe-se o caráter histórico do folclore, sua condição de sobrevivência diante do passar do tempo, e sua disseminação por uma 
determinada comunidade como caráter identitário deste grupo, como elemento de união entre seus membros e de consolidação de suas vivências em comum.

Vivência que se perdeu ou, no mínimo, foi relegada a um segundo plano diante da força da indústria cultural (ADORNO; HORKHEIMER, 1985) e mesmo da racionalização e do desencantamento do mundo trazidos por processos históricos que confluíram no capitalismo (WEBER, 2004). O capitalismo é uma estrutura social, política e econômica que, ao prezar pela utilidade e o lucro como bens máximos, tende a desprezar a fantasia e a tradição, a não ser quando elas possam ser usadas justamente em função da lucratividade (indústria cultural).

O uso que o capitalismo faz, porém, da fantasia e da tradição populares tende a "matá-las", ou seja, faz com que elas percam sua vivacidade e dinamismo, uma vez que o capitalismo as faz passar pela censura ideológica da classe dominante e as reduz a fórmulas prontas a serem repetidas inesgotavelmente, sempre em busca de um sucesso fácil e alienante.

A culpa, já associada ao Cristianismo, acima, deve ser também associada ao capitalismo e à necessidade que a ideologia dominante, a ele veiculada, traz de acumular mais e mais. O que a clássica obra de Weber ( $A$ ética protestante e o espírito do capitalismo) mais enfatiza senão a internalização do sentimento de culpa pelo estado de ócio e o orgulho e prazer em lucrar e conquistar o sucesso econômico? É justamente a apropriação ideológica do sentimento cristão de culpa que o sociólogo alemão notou e descreveu muito bem.

Por se afastar da noção de culpa e por forjar uma identidade coletiva de cunho tradicional entre os membros do grupo - enquanto o capitalismo prefere inserir em seu seio relações de concorrência e total individualismo - é que as narrativas folclóricas de Gógol apresentam-se como testemunhas de uma época pré-capitalista e como contestadoras desta estrutura histórica. Por isso, ao lê-las, não é a bruxa que causa mais espanto ao leitor; ou Viy com suas grandes pálpebras. O que mais assusta são os seres humanos, que, por pertencerem a outra lógica, bem distinta da nossa, parecem criaturas muito mais estranhas e incomuns que as bizarras entidades sobrenaturais.

\section{Referências}

ADORNO, Theodor; HORKHEIMER, Max. Dialética do Esclarecimento. Tradução de Guido Antônio de Almeida. 2a edição. Rio de Janeiro: Zahar: 1985.

BEZERRA, Paulo. Nascimento e Evolução de um Escritor. In: GÓGOL, Nikolai Vasilievich. <<O Capote>> e outras novelas de Gógol. Tradução de Paulo Bezerra. Rio de Janeiro: Civilização Brasileira, 1990, pp. 11-26. 
BÍBLIA. Português. Bíblia de Jerusalém. Vários tradutores. São Paulo: Paulus, 2002.

CASCUDO, Luís da Câmara. Folclore do Brasil (pesquisas e notas). Rio de Janeiro/São Paulo: Fundo de Cultura, 1967.

GÓGOL, Nikolai Vasilievich. O Capote. In: GÓGOL, Nikolai Vasilievich. $<<O$ Capote >> e outras novelas de Gógol. Tradução de Paulo Bezerra. Rio de Janeiro:

Civilização Brasileira, 1990a, pp. 27-58.

GÓGOL, Nikolai Vasilievich. Diário de um louco. In: GÓGOL, Nikolai Vasilievich. <<O Capote>> e outras novelas de Gógol. Tradução de Paulo Bezerra. Rio de Janeiro: Civilização Brasileira, 1990b, pp. 59-85.

GÓGOL, Nikolai Vasilievich. Noite de Natal. In: GÓGOL, Nikolai Vasilievich. $<<$ O Capote $>>$ e outras novelas de Gógol. Tradução de Paulo Bezerra. Rio de Janeiro: Civilização Brasileira, 1990c, pp. 115-165.

GÓGOL, Nikolai Vasilievich. Viy. In: GÓGOL, Nikolai Vasilievich. $<<0$ Capote >> e outras novelas de Gógol. Tradução de Paulo Bezerra. Rio de Janeiro: Civilização Brasileira, 1990d, pp. 167-207.

HOMERO. Ilíada. Tradução de Frederico Lourenço. Lisboa: Biblioteca Editores Independentes, 2007.

HOMERO. Odisseia. Tradução de Frederico Lourenço. Lisboa: Biblioteca Editores Independentes, 2008.

LACOUE-LABARTHE, P; NANCY, Jean Luc. O mito nazista. Tradução de Márcio Seligmannn-Silva. São Paulo: Iluminuras, 2002.

WEBER, Max. A ética protestante e o espírito do capitalismo. São Paulo: Cia das Letras, 2004.

\footnotetext{
i E-mail do autor: rodrigopbittencourt@gmail.com
} 